\title{
Trifluoromethanesulfonic acid promoted Dakin-West reaction: An efficient and convenient synthesis of $\beta$-acetamido ketones
}

\author{
RAVINDRA M KUMBHARE* and MADABHUSHI SRIDHAR \\ Fluoroorganics Division, Indian Institute of Chemical Technology, Hyderabad 500607, India \\ e-mail: rakumbhare@yahoo.com,kumbhare@iict.res.in
}

MS received 30 December 2010; revised 13 September 2011; accepted 22 September 2011

\begin{abstract}
Trifluoromethanesulfonic acid promoted efficient condensation of an aromatic aldehyde with an acetophenone and acetonitrile in the presence of acetylchloride as an activator producing $\beta$-acetamido carbonyl compounds is described.
\end{abstract}

Keywords. $\quad \beta$-Acetamido ketones; Dakin-West reaction; multicomponent synthesis; trifluoromethanesulfonic acid.

\section{Introduction}

$\beta$-Acetamido carbonyl compounds are valuable building blocks for the preparation of 1,3-amino alcohols ${ }^{1,2}$ or $\beta$-amino acids, ${ }^{3}$ as well as for the synthesis of various bioactive molecules such as the antibiotics nikkomycins and neopolyoxines. ${ }^{4,5}$ The conventional way for the preparation of these compounds is by the Dankin-West ${ }^{6}$ reaction using a $\alpha$-amino acid and acetic anhydride. Later on, Iqbal et al. introduced another procedure for the formation of these compounds through the condensation of an acetophenone, an aryl aldehyde in acetonitrile in the presence of $\mathrm{CoCl}_{2}{ }^{7}$ or montmorillonite K-10 clay as a catalyst and acetyl chloride as a promoter. ${ }^{8}$ Subsequently, this reaction was studied using acetyl chloride as a promoter in the presence of several other catalysts such as $\mathrm{Cu}(\mathrm{OTf})_{2} / \mathrm{Sc}(\mathrm{OTf})_{3},{ }^{9}$ $\mathrm{BiOCl},{ }^{10} \mathrm{ZrOCl}_{2} 8 \mathrm{H}_{2} \mathrm{O},{ }^{11}$ heteropoly acid, ${ }^{12,13} \mathrm{I}_{2},{ }^{14}$ amberlyst-15, ${ }^{15} \mathrm{ZnO},{ }^{16}$ and $\mathrm{CeCl}_{3}{ }^{17}$ Although all these methods are useful, they suffer from limitations such as long reaction times and the handling and disposal of inorganic acids.

Trifluoromethanesulfonic acid or triflic acid is a wellknown Bronsted super acid and it has been extensively studied as a catalyst in a wide range of organic transformations, which include cyclizations of unsaturated alcohols, ${ }^{18}$ acylations of alcohols, ${ }^{19}$ additions of allylboranes to aldehydes, ${ }^{20}$ annelation of aromatic sulfonamides, ${ }^{21}$ stereoselective Friedel-Crafts aminoalkylations of indoles and pyrroles ${ }^{22}$ etc. Here, we report

*For correspondence first observation of triflic acid promoted Dakin-West reaction of aromatic aldehydes, or acetophenones, with acetonitrile forming $\beta$-acetamido ketones in good yields (60-70\%). However, when acetyl chloride was used in the reaction as an activator, we observed formation of $\beta$-acetamido carbonyl compounds with enhanced yield (82-95\%) as shown in scheme 1. Representative results are given in table 1.

\section{Experimental}

\subsection{General procedure for the preparation} of $\beta$-acetamido ketones with triflic acid and acetyl chloride

To a stirred solution of 4-nitrobenzaldehyde $(0.30 \mathrm{~g}$, $2 \mathrm{mmol})$ and 4-nitroacetophenone $(0.33 \mathrm{~g}, 2 \mathrm{mmol})$ in acetonitrile $(5 \mathrm{~mL})$ was added acetyl chloride $(0.23 \mathrm{~g}$, $3 \mathrm{mmol})$ and trifluoromethanesulfonic acid $(0.2 \mathrm{~mL}$, $2 \mathrm{mmol}$ ). The mixture was stirred at room temperature for $30 \mathrm{~min}$. and the progress of reaction was monitored by TLC. After completion, the mixture was poured into crushed ice $(10 \mathrm{~g})$ and extracted with ethyl acetate $(2 \times 10 \mathrm{~mL})$. The organic layer was washed successively with water $(1 \times 5 \mathrm{~mL})$, saturated sodium bicarbonate solution $(1 \times 5 \mathrm{~mL})$ and brine $(1 \times 5 \mathrm{~mL})$, then dried over anhy. $\mathrm{Na}_{2} \mathrm{SO}_{4}$ and concentrated under vacuum. The crude product was purified by column chromatography to give $\beta$-acetamido- $\beta$-(4-nitrophenyl)-4nitropropiophenone as a pale yellow solid $(0.63 \mathrm{~g}, 88 \%$, mp. $\left.152^{\circ} \mathrm{C}\right)$. IR $\left(\mathrm{KBr}, \mathrm{cm}^{-1}\right)$ : 3280, 3072, 1690, 1646, 1590, 1530, 1358, 1073, 995, 816, 759. ${ }^{1} \mathrm{H}$ NMR 


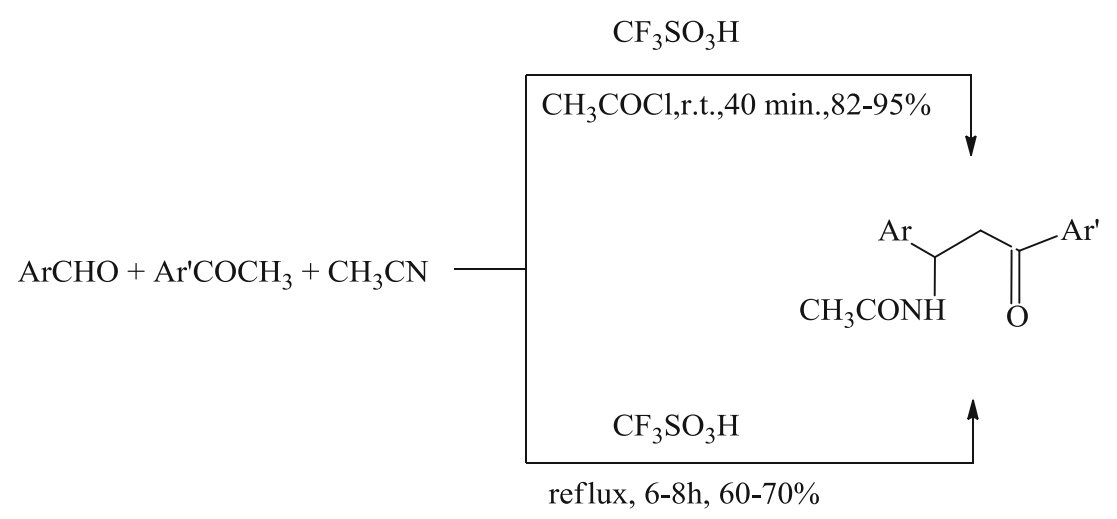

Scheme 1. Trifluoromethanesulfonic acid promoted Dakin-West reaction.

Table 1. Trifluoromethanesulfonic acid catalysed synthesis of $\beta$-acetamido carbonyl compounds.

\begin{tabular}{|c|c|c|c|c|c|c|}
\hline Entry & $\mathrm{Ar}$ & $\mathrm{Ar}^{\prime}$ & Product $^{\mathrm{a}}$ & $\begin{array}{l}\text { Time } \\
\text { Min(h) }\end{array}$ & ${ }_{{ }^{\circ} \mathrm{C}}^{\mathrm{mp}}$ & $\begin{array}{c}\text { Yield }^{c} \\
\%\end{array}$ \\
\hline 1 & $\mathrm{C}_{6} \mathrm{H}_{5}$ & $\mathrm{C}_{6} \mathrm{H}_{5}$ & & $35(8)^{\mathrm{d}}$ & $104^{\mathrm{b}}$ & $89(60)^{\mathrm{d}}$ \\
\hline 2 & $3-\mathrm{NO}_{2} \mathrm{C}_{6} \mathrm{H}_{4}$ & $\mathrm{C}_{6} \mathrm{H}_{5}$ & & $40(6)^{d}$ & 115 & $87(63)^{\mathrm{d}}$ \\
\hline 3 & $4-\mathrm{NO}_{2} \mathrm{C}_{6} \mathrm{H}_{4}$ & $\mathrm{C}_{6} \mathrm{H}_{5}$ & & $30(7)^{\mathrm{d}}$ & $150^{\mathrm{b}}$ & $89(63)^{\mathrm{d}}$ \\
\hline 4 & $4-\mathrm{ClC}_{6} \mathrm{H}_{4}$ & $\mathrm{C}_{6} \mathrm{H}_{5}$ & & $25(8)^{d}$ & $149^{b}$ & $87(62)^{d}$ \\
\hline 5 & 4- $-\mathrm{FC}_{6} \mathrm{H}_{4}$ & $\mathrm{C}_{6} \mathrm{H}_{5}$ & & $35(6)^{\mathrm{d}}$ & $120^{\mathrm{b}}$ & $86(65)^{d}$ \\
\hline 6 & $4-\mathrm{CNC}_{6} \mathrm{H}_{4}$ & $\mathrm{C}_{6} \mathrm{H}_{5}$ & & $30(7)^{\mathrm{d}}$ & $88^{\mathrm{b}}$ & $83(62)^{d}$ \\
\hline & & & $\mathrm{NH}$ & & & \\
\hline
\end{tabular}


Table 1. (continued)

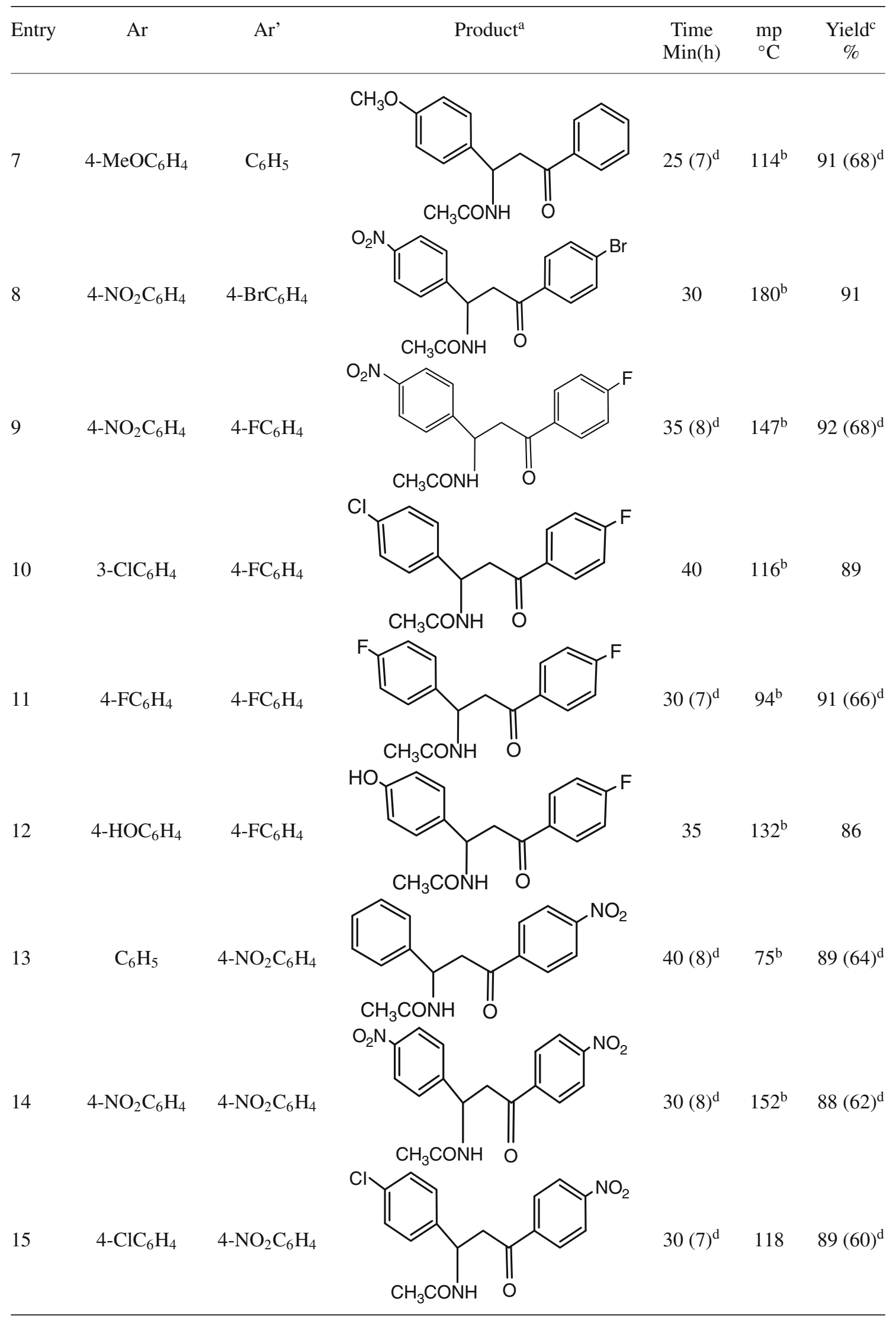


Table 1. (continued)

\begin{tabular}{|c|c|c|c|c|c|c|}
\hline Entry & $\mathrm{Ar}$ & Ar' & Product $^{\mathrm{a}}$ & $\begin{array}{l}\text { Time } \\
\text { Min(h) }\end{array}$ & $\underset{{ }^{\circ} \mathrm{C}}{\mathrm{mp}}$ & $\begin{array}{c}\text { Yield }^{\mathrm{c}} \\
\%\end{array}$ \\
\hline 16 & $4-\mathrm{FC}_{6} \mathrm{H}_{4}$ & $4-\mathrm{NO}_{2} \mathrm{C}_{6} \mathrm{H}_{5}$ & & $35(8)^{\mathrm{d}}$ & $151^{\mathrm{b}}$ & $95(70)^{\mathrm{d}}$ \\
\hline 17 & $4-\mathrm{MeC}_{6} \mathrm{H}_{4}$ & $4-\mathrm{NO}_{2} \mathrm{C}_{6} \mathrm{H}_{4}$ & & 25 & $85^{\mathrm{b}}$ & 82 \\
\hline 18 & $4-\mathrm{MeOC}_{6} \mathrm{H}_{4}$ & $4-\mathrm{NO}_{2} \mathrm{C}_{6} \mathrm{H}_{4}$ & & $30(7)^{\mathrm{d}}$ & $88^{\mathrm{b}}$ & $84(68)^{\mathrm{d}}$ \\
\hline 19 & $\mathrm{C}_{6} \mathrm{H}_{5}$ & $4-\mathrm{BrC}_{6} \mathrm{H}_{4}$ & & 40 & 99 & 86 \\
\hline 20 & $3-\mathrm{NO}_{2} \mathrm{C}_{6} \mathrm{H}_{4}$ & $4-\mathrm{BrC}_{6} \mathrm{H}_{4}$ & & $40(6)^{d}$ & $115^{\mathrm{b}}$ & $87(67)^{d}$ \\
\hline 21 & $4-\mathrm{ClC}_{6} \mathrm{H}_{4}$ & $4-\mathrm{BrC}_{6} \mathrm{H}_{4}$ & & $40(7)^{d}$ & $141^{\mathrm{b}}$ & $88(63)^{d}$ \\
\hline 22 & $4-\mathrm{FC}_{6} \mathrm{H}_{4}$ & $4-\mathrm{BrC}_{6} \mathrm{H}_{4}$ & & $35(7)^{\mathrm{d}}$ & $221^{\mathrm{b}}$ & $85(60)^{\mathrm{d}}$ \\
\hline
\end{tabular}

${ }^{\mathrm{a}}$ All products gave satisfactory IR, ${ }^{1} \mathrm{H}$ NMR, ${ }^{13} \mathrm{C}$ NMR and mass spectra. ${ }^{\mathrm{b}}$ These values were identical with the literature report. ${ }^{7,8,10,23,24}$ c Isolated yields correspond to reaction with triflic acid and acetyl chloride. ${ }^{\mathrm{d}}$ Reaction times and yield given in parentheses correspond to the reaction with triflic acid.

(DMSO-D $6,200 \mathrm{MHz}): \delta 1.90(\mathrm{~s}, 3 \mathrm{H}), 3.4(\mathrm{dd}, J=5.7$ and $13.8 \mathrm{~Hz}, 1 \mathrm{H}), 3.7(\mathrm{dd}, J=7.3$ and $13.8 \mathrm{~Hz}, 1 \mathrm{H})$, $5.5(\mathrm{dd},, J=7.3$ and $5.7 \mathrm{~Hz}, 1 \mathrm{H}), 7.62(\mathrm{~d}, J=$ $8.9 \mathrm{~Hz}, 1 \mathrm{H}), 8.1-8.2(\mathrm{~m}, 4 \mathrm{H}), 8.2-8.4(\mathrm{~m}, 4 \mathrm{H}) ;{ }^{13} \mathrm{C}$ NMR (DMSO-D $6,50 \mathrm{MHz}): \delta 22.4,44.3,48.5,123.1$, $123.5,127.7,129.1,140.7,146.3,149.8,150.1,169.1$, 195.3; FABMS: 358( $\left.\mathrm{M}^{+}+1\right)$.

\subsection{General procedure for the preparation} of $\beta$-acetamido ketones with triflic acid

To a stirred solution of 4-anisaldehyde $(0.27 \mathrm{~g}, 2 \mathrm{mmol})$ and acetophenone $(0.24 \mathrm{~g}, 2 \mathrm{mmol})$ in acetonitrile $(5 \mathrm{~mL})$ were added triflic acid $(0.2 \mathrm{~mL}, 2 \mathrm{mmol})$. The mixture was refluxed for $7 \mathrm{~h}$ and the progress of the 


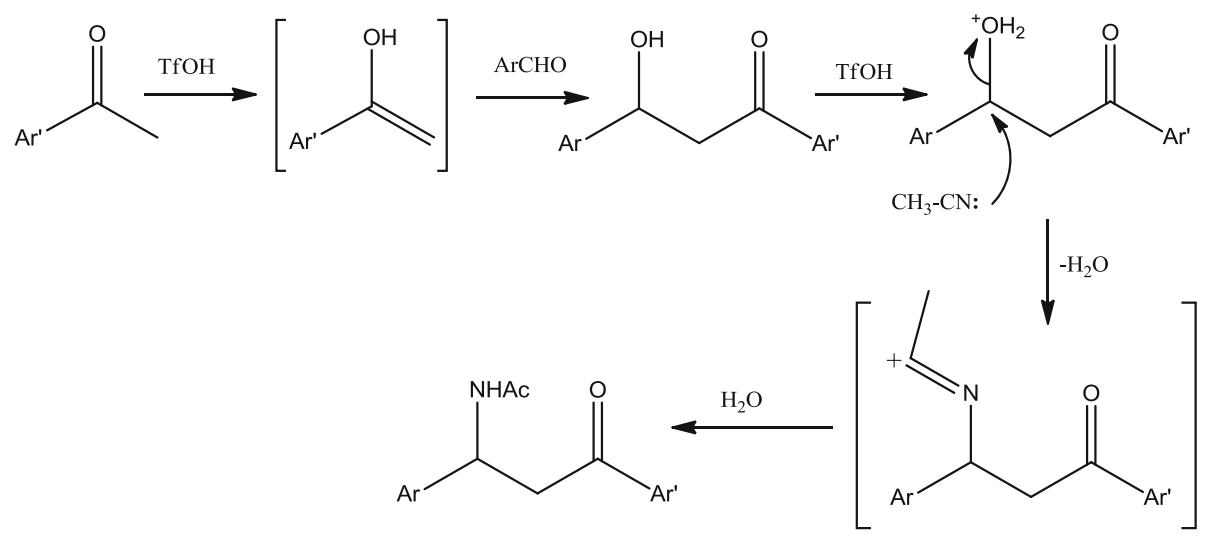

Scheme 2. Plausible mechanism for the triflic acid promoted Dakin-West reaction.

reaction was followed by TLC. After completion of the reaction, the mixture was poured into crushed ice $(10 \mathrm{~g})$ and extracted with ethyl acetate $(2 \times 10 \mathrm{~mL})$. The organic layer was washed with water $(1 \times 5 \mathrm{ml})$, saturated sodium bicarbonate solution $(1 \times 5 \mathrm{~mL})$ and brine $(1 \times 5 \mathrm{~mL})$, dried over anhy. $\mathrm{Na}_{2} \mathrm{SO}_{4}$ and concentrated under vacuum. The crude product was purified by normal column chromatography to obtain $\beta$-acetamido$\beta$-(4-methoxyphenyl) propiophenone as yellowish solid $\left(0.40 \mathrm{~g}, 68 \%, \mathrm{mp} 114^{\circ} \mathrm{C}\right)$. The isolated product gave the following spectral data: IR $\left(\mathrm{KBr}, \mathrm{cm}^{-1}\right) 302,3075$, 2934, 1689, 1648, 1546, 1296, 1103, 887, 825.

${ }^{1} \mathrm{HNMR}$ (DMSO-D, $\left.200 \mathrm{MHz}\right): \delta 2.0(\mathrm{~s}, 3 \mathrm{H}), 3.3$ (dd, $J=6.8$ and $16.6 \mathrm{~Hz}, 1 \mathrm{H}), 3.7(\mathrm{dd}, J=5.3$ and $16.6 \mathrm{~Hz}$, $1 \mathrm{H}), 5.5(\mathrm{dd}, J=5.3$ and $6.8 \mathrm{~Hz}, 1 \mathrm{H}), 6.8(\mathrm{~d}, J=8.9$, 2H), $7.2(\mathrm{~d}, J=8.9,2 \mathrm{H}), 7.4-7.5(\mathrm{~m}, 3 \mathrm{H}), 7.9(\mathrm{~d}, J=$ $7.6 \mathrm{~Hz}, 2 \mathrm{H}) ;{ }^{13} \mathrm{C}$ NMR $\left(\mathrm{DMSO}_{6}, 50 \mathrm{MHz}\right): \delta 22.2$, 44.5, 49.0, 55.1, 101.0, 127.1, 128.2, 129.7, 133.1, 134.7, 136.3, 158.4, 169.1, 197.2. FABMS: $298(\mathrm{M}+\mathrm{H})^{+}$.

\section{Results and discussion}

In most of the existing literature on Lewis acid catalysed Dakin-West reaction, acetyl chloride was widely used as an activator to promote the reaction. Later $\mathrm{TMSCl}^{13}$ was also reported be a useful activator for promoting the Dakin-West reactions. In our study, we found efficient Dakin-West reactions with triflic acid alone without requiring acetyl chloride and obtained $\beta$-acetamido carbonyl compounds in $60-70 \%$ under reflux in acetonitrile. However, when this reaction was carried out using triflic acid as a catalyst and acetyl chloride as a promoter, reaction proceeded at room temperature producing $\beta$-acetamido carbonyl compounds with improved yields (82-95\%). A plausible pathway for the formation of $\beta$-acetamido carbonyl compounds under both conditions, i.e., using triflic acid alone and also by using both triflic acid and acetyl chloride, are shown in schemes 2 and 3, respectively.

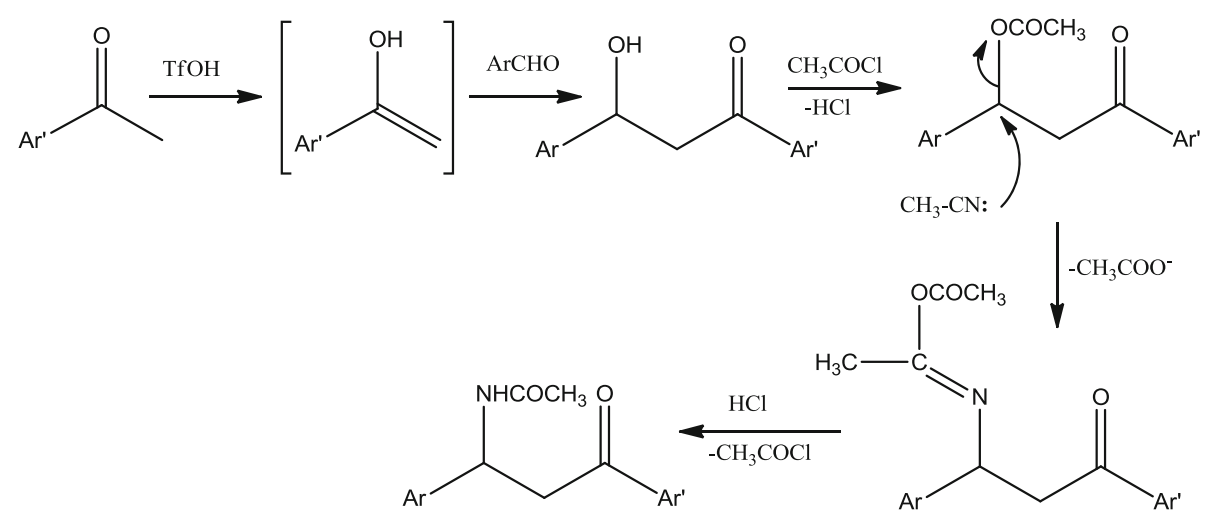

Scheme 3. Plausible mechanism for the triflic acid catalysed Dakin-West reaction in the presence of acetyl chloride as an activator. 


\section{Conclusion}

In conclusion, the present work describes an efficient condensation of an aromatic aldehyde and acetophenones with acetonitrile using triflic acid as a promoter and acetyl chloride as an activator producing $\beta$-acetamido carbonyl compounds in good yields.

\section{Acknowledgements}

We are thankful to Dr. J S Yadav, Director, Indian Institute of Chemical Technology (IICT) for providing facilities and one of us (RMK) thanks S.E.R.C., Department of Science and Technology, Government of India for financial assistance under the Fast Track Scheme for young scientists (SR/FTP/CS-93/2006).

\section{References}

1. Barluenga J, Viado A L, Aguilar E, Fustero S and Olano B 1993 J. Org. Chem. 585972

2. Enders D, Moser M, Geibel G and Laufer M C 2004 Synthesis 122040

3. Mukhopadhyay M, Bhatia B and Iqbal J 1997 Tetrahedron Lett. 381083

4. Kobinata K, Uramoto M, Nishii M, Kusakabe H, Nakamura G and Isono K 1980 Agric. Biol. Chem. 44 1709

5. Daehn U, Hagenmaier H, Hoehne H, Koenig W A, Wolf G and Zaehner H 1976 Arch. Microbiol. 107249
6. Dakin H D and West R 1928 J. Biol. Chem. 78745

7. Rao I N, Prabhakaran E N, Das S K and Iqbal J 2003 J. Org. Chem. 684079

8. Bahulayan D, Das S K and Iqbal J 2003 J. Org. Chem. 685735

9. Pandey G, Singh R P, Garg A and Singh V K 2005 Tetrahedron Lett. 462137

10. Ghosh R, Maiti S and Chakraborty A 2005 Synlett. 1115

11. Ghosh R, Maiti S, Chakraborty A, Chakraborty S and Mukherjee A K 2006 Tetrahedron 624059

12. Heravi M M, Ranjbar L, Derikvand F and Bamoharram F F 2007 Catal. Commun. 8289

13. Heravi M M, Ranjbar L, Derikvand F and Bamoharram F F 2007 J. Mol. Catal., A Chem. 27128

14. Das B, Reddy K R, Ramu R, Thirupathi P and Ravikanth B 2006 Synlett. 111756

15. Das B and Reddy K R 2006 Helv. Chim. Acta 893109

16. Maghsoodlou M T, Hassankhani A, Shaterian H R, Habibi Khorasani S M and Mosaddegh E 2007 Tetrahedron Lett. 481729

17. Khan A T, Choudhury L H, Parvin T and Ali M A 2006 Tetrahedron Lett. 478137

18. Coulombel L and Dunach E 2004 Green Chem. 6499

19. Dumeunier R and Marko I E 2004 Tetrahedron Lett. 45 825

20. Carosi L, Lachance H and Hall D G 2005 Tetrahedron Lett. 468981

21. Abid M, Teixeira L and Török B 2007 Tetrahedron Lett. 484047

22. Abid M, Teixeira L and Török B 2008 Org. Lett. 10933

23. Rafiee E, Tark F and Joshaghani M 2006 Bio. Med. Chem. Lett. 161221

24. Ghosh R, Maiti S and Chakraborty A 2005 Synlett 01 115 